\title{
Pond Head Level Control in a Run-of-River Hydro Power Plant using Fuzzy Controller
}

\author{
Omkar Yadav ${ }^{\#}$, Nand Kishor ${ }^{\#}$, Member, IEEE, Jesus Fraile-Ardanuy*, Soumya R Mohanty ${ }^{\#}$, Member, \\ IEEE, Juan I. Pérez ${ }^{+}$, José I. Sarasúa ${ }^{+}$
}

\begin{abstract}
The run-of-river hydro power plant usually have low or nil water storage capacity, and therefore an adequate control strategy is required to keep the water level constant in pond. This paper presents a novel technique based on TSK fuzzy controller to maintain the pond head constant. The performance is investigated over a wide range of hill curve of hydro turbine. The results are compared with PI controller as discussed in [1].
\end{abstract}

Index Terms-- Run-of-river; Head level; TSK fuzzy controller

Nomenclature

$A_{\text {hpond }}$ Head pond area $\left(\mathrm{m}^{2}\right)$

$A_{s t} \quad$ Surge tank cross sectional area $\left(\mathrm{m}^{2}\right)$

$A_{h c} \quad$ Head-race conduit cross sectional area $\left(\mathrm{m}^{2}\right)$

$A_{\text {th }} \quad$ Minimum surge tank cross sectional area according to Thoma criterion $\left(\mathrm{m}^{2}\right)$

$b_{i j} \quad$ Parameters of the linearized turbine equations

$K_{r h c} \quad$ Head-race conduit losses coefficient

$a_{g} \quad$ Gravity acceleration $\left(\mathrm{m} / \mathrm{s}^{2}\right)$

$H \quad$ Net head (m)

$H_{\text {base }} \quad$ Base head (m)

$H_{\text {hpond }} \quad$ Gross head in the head pond (m)

$Q_{s w} \quad$ Flow spilled over spillway $\left(\mathrm{m}^{3} / \mathrm{s}\right)$

$H_{\text {ref }} \quad$ Reference height in the head pond (m) with respect to the tail water level

$H_{s t} \quad$ Surge tank level (m) with respect to tail water level

$K \quad$ Proportional gain of PI controller

$L_{h c} \quad$ Head-race conduit length (m)

p $\quad K_{\text {rhc }} Q_{\text {base }}^{2} / H_{\text {base }}$

$Q \quad$ Turbine flow $\left(\mathrm{m}^{3} / \mathrm{s}\right)$

$Q_{\text {base }} \quad$ Base flow $\left(\mathrm{m}^{3} / \mathrm{sec}\right)$

$Q_{\text {riv }} \quad$ River flow $\left(\mathrm{m}^{3} / \mathrm{s}\right)$

$Q_{h c} \quad$ Head race conduit flow $\left(\mathrm{m}^{3} / \mathrm{s}\right)$

$q_{h c}{ }^{0} \quad$ Initial head-race conduit flow (p.u.)

$T_{i} \quad$ Integral time constant of the I controller (s)

$W \quad$ Wicket gates opening $(\mathrm{mm})$

$W_{\text {base }} \quad$ Base value of the wicket gates opening (mm)

${ }^{\#}$ Mr. Omkar Yadav, Dr. Nand Kishor, Soumya R Mohanty are associated with Department of Electrical Engineering, Motilal Nehru National Institute of Technology ${ }^{\#}$ Allahabad India.

"Dr. Jesus Fraile-Ardanuy Dpto. TEAT, ETSI Telecomunicación, UPM, Spain Dr. J.I. Pérez-Díaz and Dr. I. Sarasúa Jesus are with Dpto. Ing. Civil: Hidráulica y Energética. ETSI Caminos, Canales y Puertos, UPM, Spain

\section{INTRODUCTION}

$\mathrm{R}$ UN- Run-of-river hydropower plants are increasingly gained importance around the world, mainly due to their lower environmental impact over hydro plants associated to reservoirs with large water storage capacity [1]. In the conventional hydro power plant with large reservoir the turbine governor adjusts the wicket gates position to supply variable power during periods of peak demand providing the electric grid with operational flexibility. This operation scheme, referred to in the technical literature as load-following, can lead to fluctuating hydrologic patterns in the downstream river that can cause in some cases considerable ecological damage to downstream riparian and aquatic eco-systems. As a result, this issue has nowadays received policy concern, to the extent that in several industrialized countries their regulatory authorities have adopted review or re-license process of hydropower projects and forcing them to change from peaking operation to run-of-river operation [5].

Because of their smaller size and power capacity run-ofriver hydro power plants are considered as intermittent renewable energy source and do not contribute significantly to load-frequency control problem and therefore their control strategy can be designed to get the best possible tracking of the available river flow. The behavior of this control system is quite different from the traditional load-frequency regulator, especially in a diversion configuration, where high inertia elements are interposed between the controlled variable (water level) and the control variable (wicket gates position).

For this purpose, a control system aimed to maintain a constant water level in the head pond is discussed in [1-3], [6]. The authors in [1] have used conventional PI controller technique to maintain head level constant irrespective of changes in river flow. However, such approach leads to tune and thus determine the PI gains suitable to give satisfactory response in each operating zone of hill curves. Thus a control scheme that does require to be tuned over different conditions needs to be tested in such issues.

The aim of this paper is to analyze the response with use of TSK fuzzy control scheme in a run-of-river hydro power plant. TSK fuzzy water level controller is used to obtain an adequate plant response in each operating zone. Section II describes the modeling of run-of-river hydro power plant, followed by control schemes in section III. Lastly discussion on results and conclusion derived from the study is given in section IV and $\mathrm{V}$ respectively. 


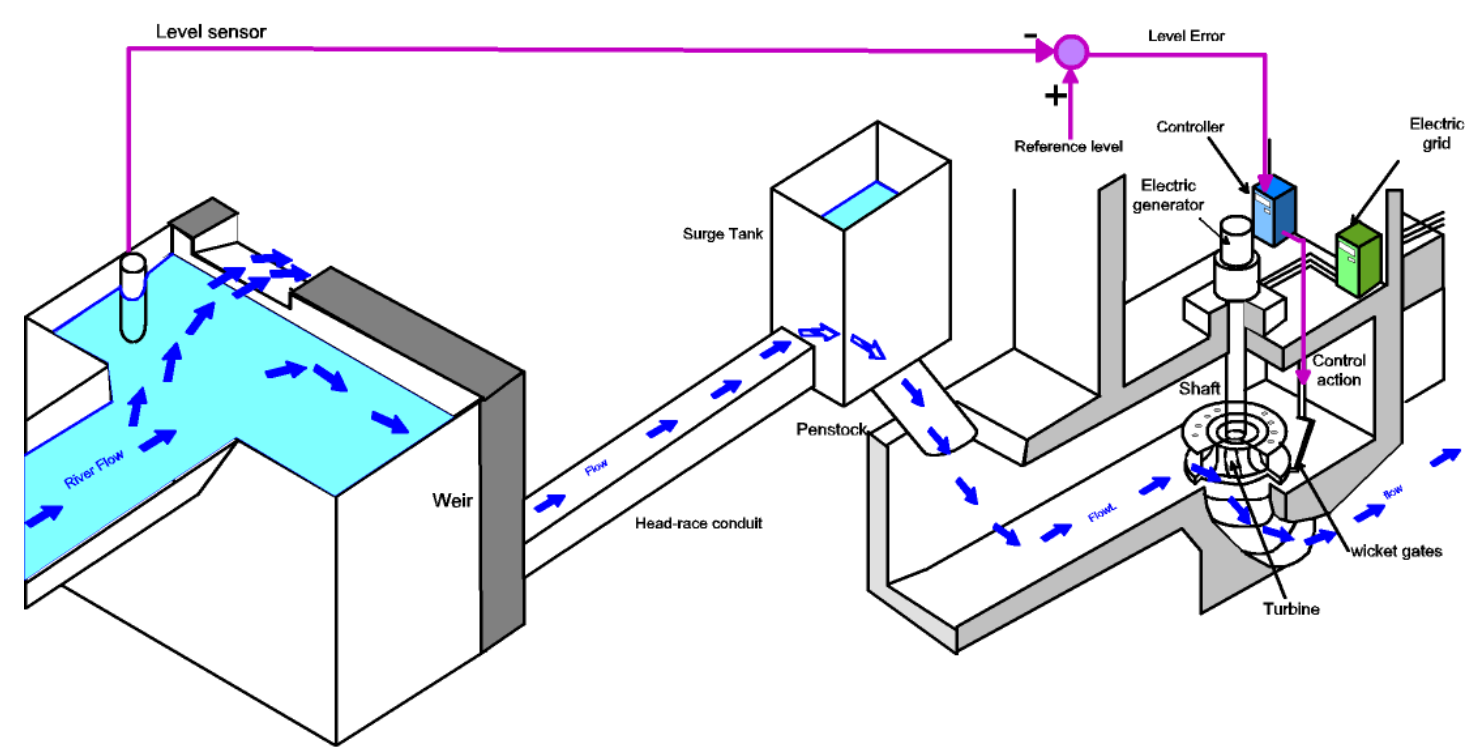

Fig 1. Run of river small hydro power plant with head race conduit

\section{MODEL DESCRIPTION}

The schematic diagram of run-of-river hydro power plant is shown in Fig. 1 [1]. Since the time response of electromechanical system are much faster than hydraulic system [4], the speed variations caused due to changes in turbine flow have not been considered in this model. Thus speed may be assumed to remain constant at its synchronous value and associated speed regulation problem is not modeled in this paper.

In this section the dynamic model of a run-of-river hydro power plant with pressurized conduits as in Fig.1 is described.

\section{A. Hydraulic system}

Head pond

$$
A_{\text {hpond }} \frac{d}{d t} H_{\text {hpond }}=Q_{r i v}-Q_{h c}-Q_{s w}
$$

Head race conduit

$$
\frac{L_{h c}}{a_{g} A_{h c}} \frac{d}{d t} Q_{h c}+K_{r h c}\left|Q_{h c}\right| Q_{h c}=H_{h p o n d}-H_{s t}
$$

Surge Tank

$$
A_{s t} \frac{d}{d t} H_{s t}=Q_{h c}-Q
$$

Turbine-Penstock

$$
\left[\left[\left(\frac{H}{H_{\text {base }}}-h_{s t}\right) b_{11}+\left(\frac{W}{W_{\text {base }}}-\tau_{0}\right) b_{13}\right]+q_{0}\right] Q_{\text {base }}=Q
$$

Since, the dynamics of the penstock-turbine subsystem is very fast, compared with the responses of interest for this study, so a static model is used.

The hill curves of a Francis hydro turbine as shown in Fig. 2 [1] is used to describe the operating regions; zone I, zone II and zone III.

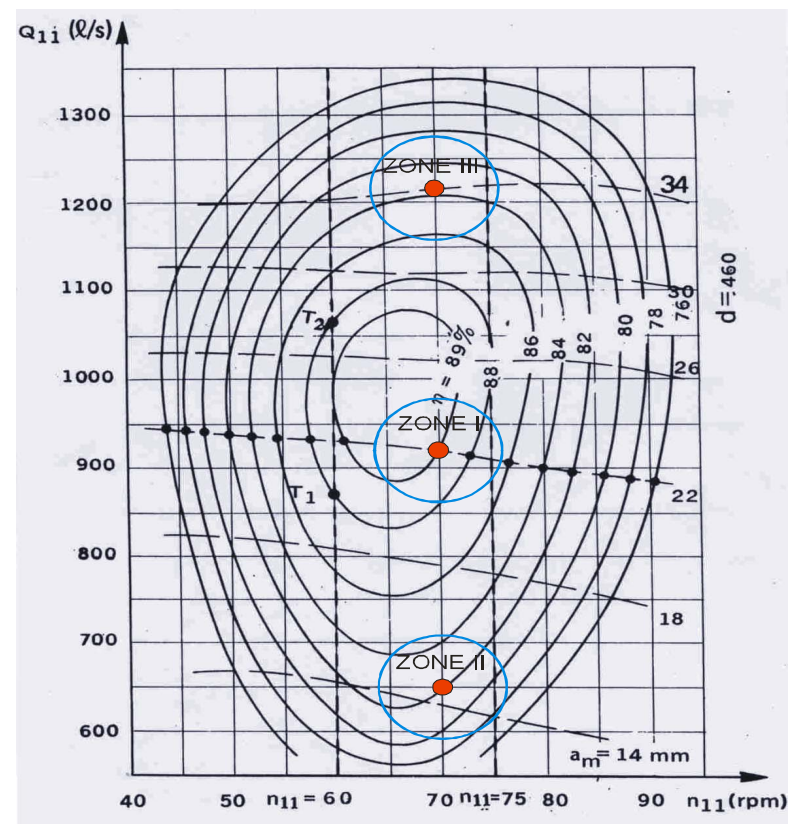

Fig. 2. Hill Curves of Francis hydro turbine

Table I and II gives the specifications of hydro plant and hydro turbine respectively as used in study [1]. The value of turbine parameters is defined in each zone of operating regions.

\section{CONTROLleR SCHEMES}

The controller scheme of hydro plant implemented to keep pond head constant irrespective of hydro turbine operating zone is shown in Fig. 3.

\section{A. PI Controller}

The PI controller to modify the wicket gates position to maintain a constant water level in the head pond can be defined as: 


$$
\frac{d w}{d t}=\frac{H_{\text {hpond }}-H_{r e f}}{T_{i}}+K \frac{d\left(H_{\text {hpond }}-H_{r e f}\right)}{d t}
$$

The PI gains are determined by linearizing the above equations around an operating point. The Routh-Hurwitz criterion was analyzed and PI gains tuned to each operating point through root locus were obtained [1], [7].

\section{B. TSK fuzzy controller}

Fuzzy system algorithms offers, in fact many advantages over traditional controls since they give fast convergence, are parameter insensitive, and accept noisy and inaccurate signals. These systems can be used to any inference system in which the output membership functions are either linear or constant. A typical rule in a Sugeno fuzzy model has the form:

If input $1=X$, input $2=Y$, then output is $Z=a \cdot X+b \cdot Y+c$ For a zero order model, the output level $Z$ is a constant $($ i.e., $a=b=0)$. The output level $Z_{i}$ of each rule is weighted by the firing strength $W_{i}$ of the rule. For example, for an AND rule with input $1=X$ and input $2=Y$, the firing strength is $W_{i}=\operatorname{AndMethod}\left(F_{1}(x), F_{2}(y)\right)$. Where $\quad F_{1,2}($.$) are the$ membership functions for input 1 and 2 . The final output of the system is the weighted average of all rule outputs, computed as:

$$
\text { Final output }=\frac{\sum_{i=1}^{N} W_{i} Z_{i}}{\sum_{i=1}^{N} W_{i}}
$$

Where $\mathrm{N}$ is the number of rules.

In this paper TSK fuzzy controller is used to control the opening of wicket gate of the turbine. Error and rate of change in error are the two inputs; $X$ and $Y$ of the TSK controller. The block diagram that explains the operation of TSK fuzzy controller is shown in Fig. 4. The rules are set in the form of a matrix following a conventional approach as given in Table III. The linguistic variables are defined as $\{\mathrm{N}, \mathrm{Z}, \mathrm{P}\}$, where $\mathrm{N}$ means negative, $\mathrm{Z}$ means zero, $\mathrm{P}$ means positive.

TABLE I.

POWER PLANT DATA

\begin{tabular}{|l|l|}
\hline Parameter & Value \\
\hline Head pond area $A_{\text {hpond }}$ & $2070.00 \mathrm{~m}^{2}$ \\
\hline Surge tank area $A_{\text {st }}$ & $30.00 \mathrm{~m}^{2}$ \\
\hline Thoma area $A_{\text {th }}$ & $22.74 \mathrm{~m}^{2}$ \\
\hline$n$ & 1.32 \\
\hline$m$ & 69.01 \\
\hline
\end{tabular}

TABLE II

TURBINE PARAMETERS

\begin{tabular}{|l|l|l|l|}
\hline & ZONE I & ZONE II & ZONE III \\
\hline $\boldsymbol{Q}_{\text {base }}$ & 14.40 & 9.86 & 19.08 \\
\hline$q_{\text {hc }}^{0}$ & 1,000 & 0,685 & 1,33 \\
\hline $\boldsymbol{b}_{\mathbf{1 1}}$ & 0,547 & 0,421 & 0,630 \\
\hline $\boldsymbol{b}_{\mathbf{1 3}}$ & 0,777 & 0,876 & 0,597 \\
\hline
\end{tabular}

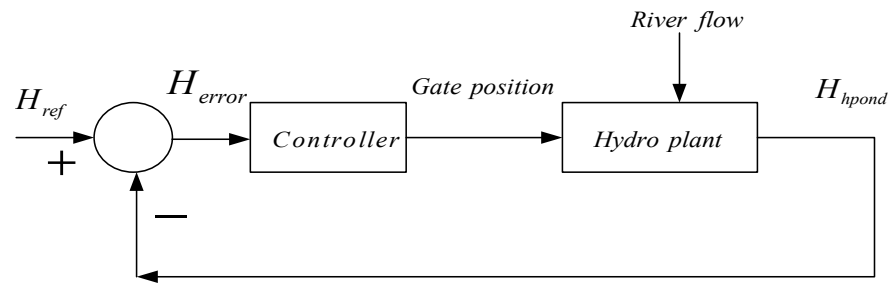

Fig. 3. Hydro plant controller scheme

TABLE III

FUZZY INFERENCE RULES

\begin{tabular}{|l|c|c|c|c|}
\hline \multicolumn{2}{|c|}{$F_{1,2}()}$. & \multicolumn{3}{|c|}{ Error } \\
\cline { 3 - 5 } \multicolumn{2}{|c|}{} & $\mathrm{N}$ & $\mathrm{Z}$ & $\mathrm{P}$ \\
\hline $\begin{array}{l}\text { Rate of } \\
\text { change in } \\
\text { error }\end{array}$ & $\mathrm{N}$ & $\mathrm{N}$ & $\mathrm{P}$ & $\mathrm{Z}$ \\
\cline { 2 - 5 } & $\mathrm{Z}$ & $\mathrm{P}$ & $\mathrm{Z}$ & $\mathrm{N}$ \\
\cline { 2 - 5 } & $\mathrm{P}$ & $\mathrm{Z}$ & $\mathrm{N}$ & $\mathrm{P}$ \\
\hline
\end{tabular}

\section{Simulation Of Power Plant Response}

The authors [1] have discussed use of PI controller to maintain water level in head pond constant. The PI gains were determined according to initial river flow in different operating regions; zone I, zone II and zone III of hill curves.

The triangular shape input membership for change in error and rate of change of error is shown in Fig. 5. The comparative performance with proposed fuzzy controller is investigated under two different studies; (A) river flow change in each zone and (B) river flow change between zones of hill curves.

\section{A. Change in river flow in each zone}

The results are simulated with plant parameters and initial river flow conditions as defined in each zone on hill curves. The river flow is assumed to vary as "Gaussian" function by $10 \%$ from its initial value, because river flow does not change instantly as step function.

Case (i): The initial river flow status in zone I is $14.4 \mathrm{~m}^{3} / \mathrm{sec}$. With use of turbine parameters as of zone II from hill curves, the plant model is simulated. The variation of water level in head pond, head race conduit flow, surge tank water level and gate position towards the disturbance in river flow is shown in Fig. 6. As observed, the TSK fuzzy controller maintains the water level in head pond accurately and effectively with response due to PI controller being slow. The PI gains corresponding to zone II as discussed in [1] is used.

Case (ii): The initial river flow in zone II is $9.86 \mathrm{~m}^{3} / \mathrm{sec}$. The turbine parameters as of zone I and change in initial river flow as mentioned above is simulated. The response of different variables of plant is illustrated in Fig. 7. The variation due to TSK controller remains satisfactory with respect to those obtained by PI controller.

Case (iii): As above, the plant response is obtained with initial river flow $19.08 \mathrm{~m}^{3} / \mathrm{sec}$ corresponding to zone III and shown in Fig. 8.

In the above study, it is further indicated that gate opening due to TSK controller follows the "Gaussian" function variation of river flow. 


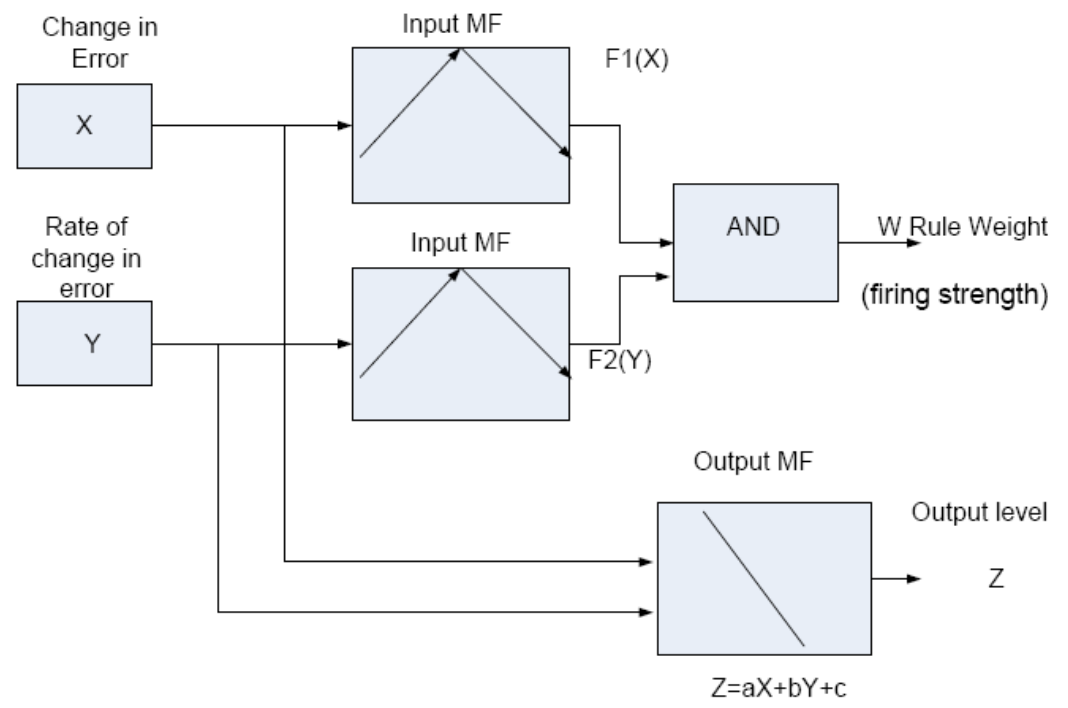

Fig. 4 Illustration of TSK fuzzy controller

\section{B. Change in river flow between zones}

In this study, the disturbance in river flow is assumed to be set with initial and final values corresponding to two different zones of hill curves.

Case (i): The initial river flow is set at $14.4 \mathrm{~m}^{3} / \mathrm{sec}$ (zone I) and changed to $9.86 \mathrm{~m}^{3} / \mathrm{sec}$ (zone II) with its disturbance variation as "Gaussian" function. The turbine parameters and PI gains corresponding to zone II is set for simulation. The comparative performance of two controllers is given in Fig. 9. Case (ii): The initial river flow is set at $14.4 \mathrm{~m}^{3} / \mathrm{sec}$ (zone I) and changed to $19.08 \mathrm{~m}^{3} / \mathrm{sec}$ (zone III). The plant response is shown in Fig. 10. The variation in pond head due to use of TSK controller reaches to reference set point as a more gradual and smooth transition.

However, as compare to the results obtained [1] with use of PI gains adjusted to zone III, when the plant operates in zone II, an unstable behavior was observed. (see Fig. 10 in [1]).

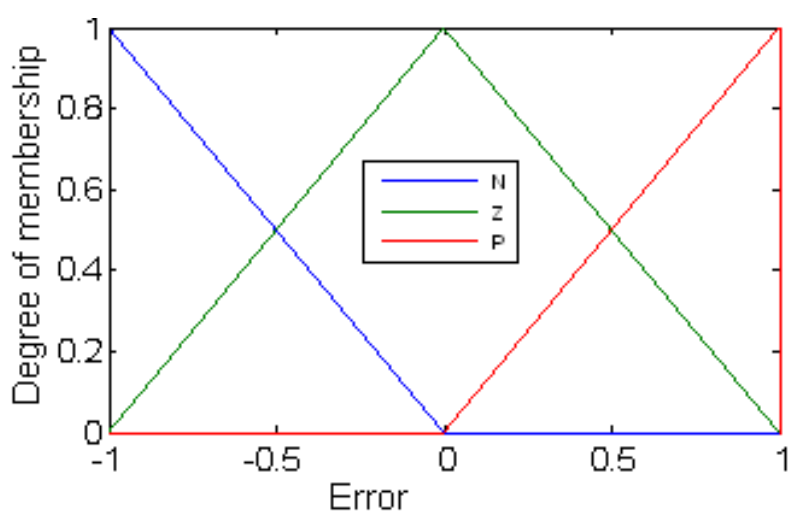

(a) Change in error

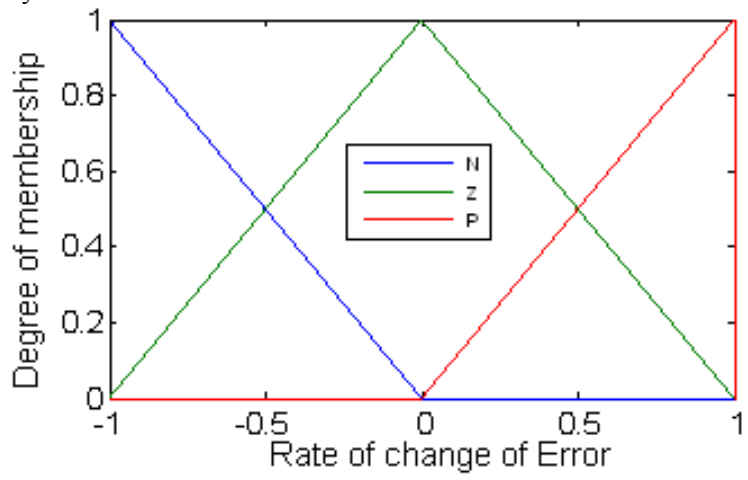

(b) Rate of change in error

Fig. 5 Input membership functions
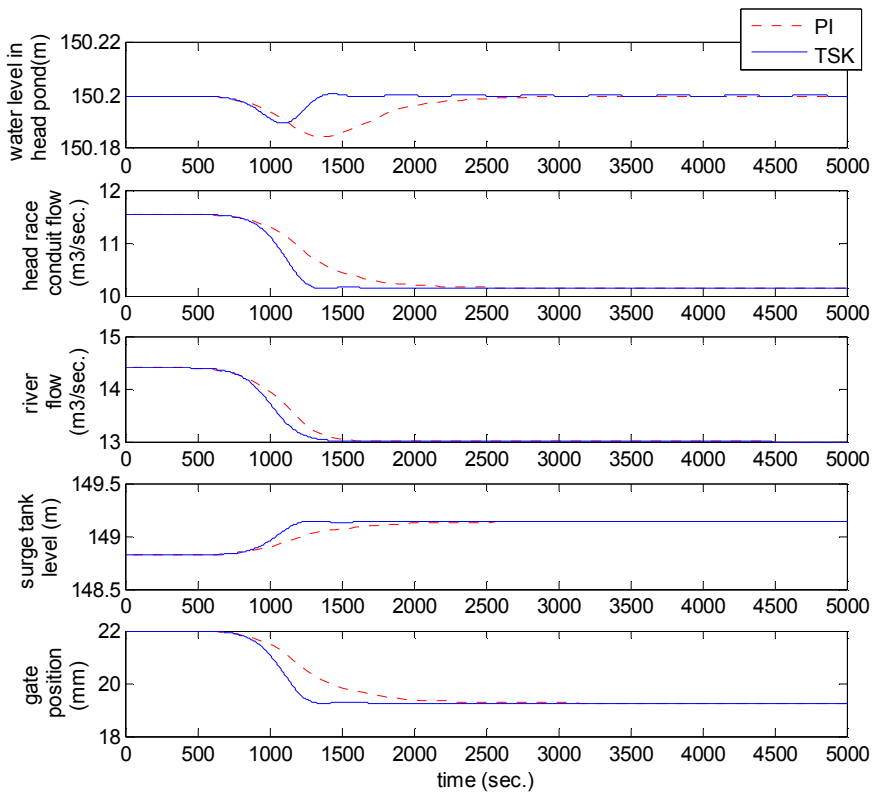

Fig. 6 Plant response in zone I with $10 \%$ disturbance in initial river flow 

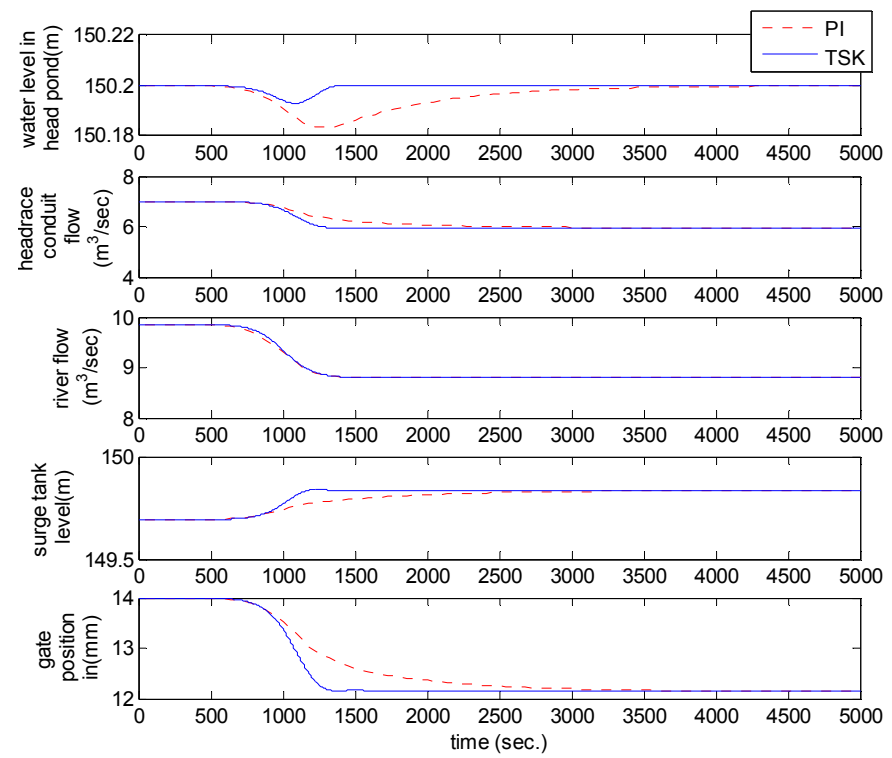

Fig. 7 Plant response in zone II with $10 \%$ disturbance in initial river flow
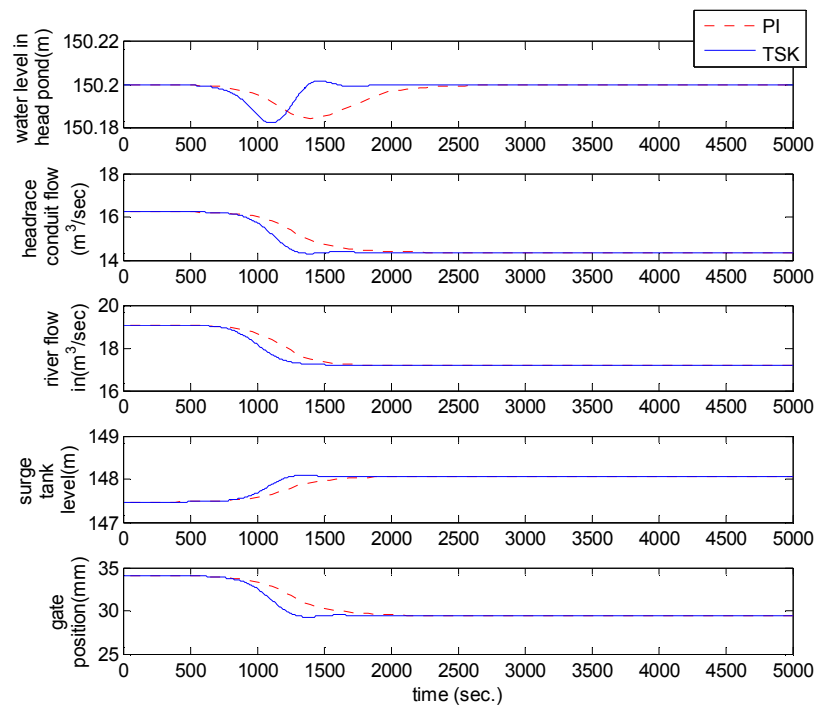

Fig. 8 Plant response in zone III with $10 \%$ disturbance in initial river flow
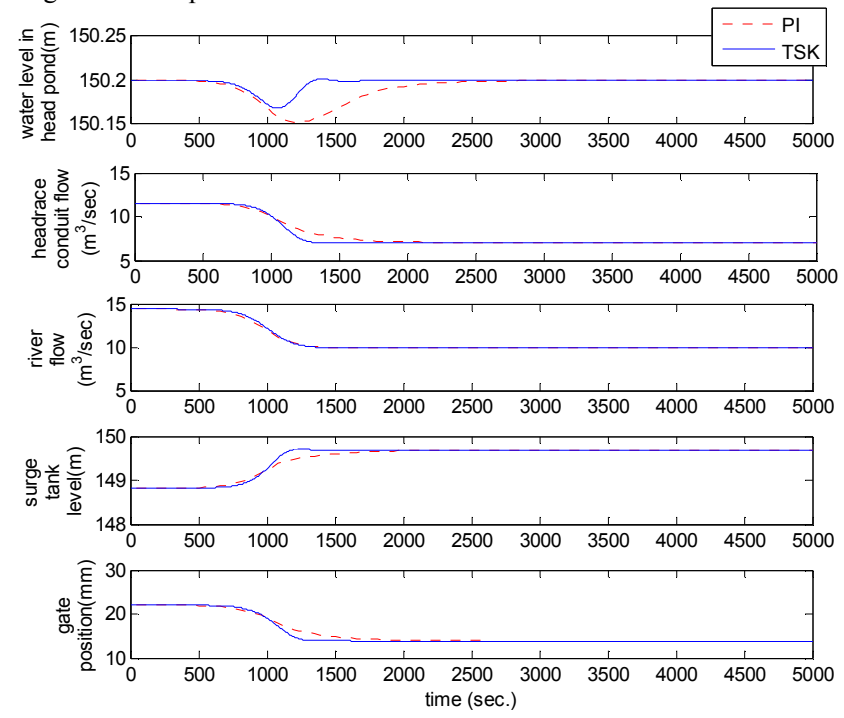

Fig. 9 Plant response with river flow changed from zone I to zone II
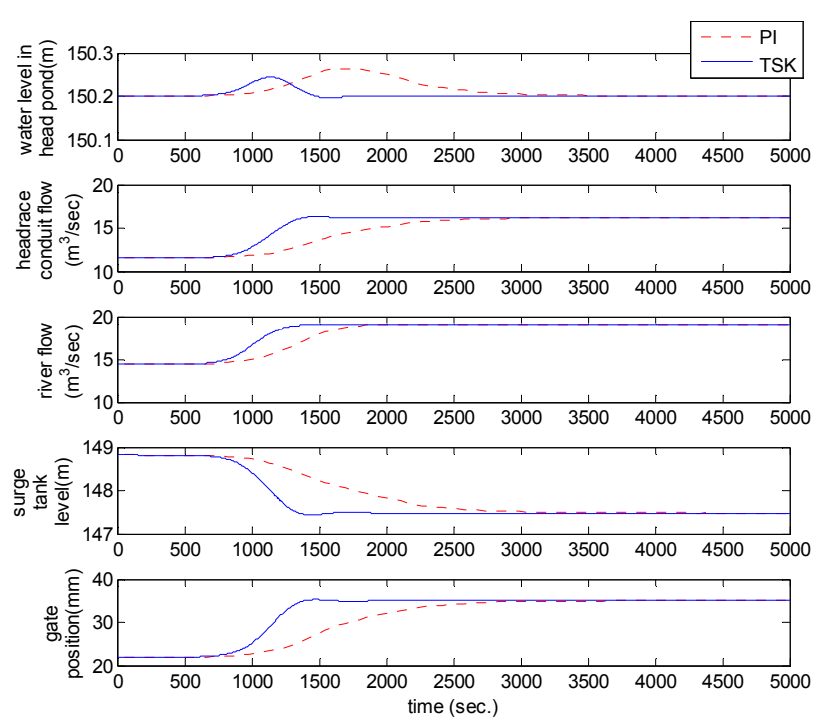

Fig. 10 Plant response with river flow changed from zone I to zone III

\section{CONCLUSION}

The main contribution of the study presented was the investigation of TSK fuzzy controller to maintain water level constant in run-of-river hydro power plant. The response of hydro power plant was simulated with $10 \%$ disturbance in river flow from initial condition in three different operating zones of hill curves. Also the performance of TSK fuzzy controller was observed with widely varied disturbance in river flow between two operating zones. The proposed controller scheme varied the wicket gate position in a fashion that allowed a smooth with minimum time variation in surge tank level and head race conduit flow.

Thus, the result of this work demonstrates the goodness of proposed fuzzy controller, which is able to stabilize the plant at any point of operation compared to previous publication [1].

\section{REFERENCES}

[1] J. I. Sarasua, J. J. Fraile-Ardanuy, J. I. Perez-Diaz, J. R. Wilhelmi and J. A. Sanchez, "Control of a run of river small hydro power plant", in Proc. of International conference on power Engineering, Energy and Electric Drives, Setubal, Portugal, April 12-14, 2007.

[2] A. H. Glattfelder and L. Huser, "Hydropower Reservoir Level Control: A Case Study", Automatica, Vol. 29, No. 5, pp 1203-1214, 1993.

[3] K. Takeda and K. Kurotani, "Water Level Regulating System", US Patent, No.5472312, 1995.

[4] J. J. Fraile-Ardanuy, J. I. Pérez, I. Sarasúa, J. R. Wilhelmi and J. FraileMora, "Speed control of run-of-river variable speed hydro plants", in Proc. of the International Conference on Renewable Energy and Power Quality, ICREPQ'06, Palma de Mallorca, Spain, April 2006.

[5] J. I. Pérez-Díaz, J. I. Sarasúa, J. Fraile-Ardanuy, J. R. Wilhelmi and J. A. Sánchez, "A control system for low-head diversion run-of-river small hydro plants with pressure conduits considering the tailwater level variation", in Proc. Of the International Conference on Renewable Energy and Power Quality, ICREPQ 2010, Granada, Spain, March, 2010.

[6] Legros, J. M., Mondon, C. and Libaux, A. "EDF Hydtopower plants operation: new challenges and technical solutions", Waterpower XCVI, Spokane, WA, USA, July 2009.

[7] Sarasúa, J. I. "Control de minicentrales fluyentes. Modelado y estabilidad" (PhD dissertation). Technical University of Madrid, 2009. Availabel (in Spanish): http://oa.upm.es/1568/. 